\title{
Relationship between Foot Pain/Deformities and Risk of Fall in Patients with Rheumatoid Arthritis
}

\author{
H Guler ${ }^{1}$, MT Yildizgoren ${ }^{1}$, N Ustun ${ }^{1}$, A Balci ${ }^{2}$, S Karazincir ${ }^{2}$, C Ozer $^{3}$, AD Turhanoglu ${ }^{1}$
}

\begin{abstract}
Objective: Patients with rheumatoid arthritis (RA) have an increased risk of falls. Foot pain/ deformities affect the majority of patients with $R A$. The objective of this study was to determine the influence of foot pain/deformities on risk of fall in patients with $R A$.

Methods: This study comprised 89 patients (75 females, 14 males) with RA. Patients were queried about pain in the hip, knee and foot. The diagnoses of foot deformities were based on clinical and radiographic evaluation. Patients' risk of fall was assessed using the Tinetti Performance Oriented Mobility Assessment (TPOMA).

Results: Mean age and disease duration of the patients were $46.84 \pm 13.20$ and $7.82 \pm 7.01$ years, respectively. Twelve (13\%) patients had risk of fall. The patients with risk of fall had a higher numeric rating scale (NRS) for foot pain (4.08 \pm 1.44 vs $2.62 \pm 2.51 ; \mathrm{p}=0.012)$ and number of foot deformities $(1.41 \pm 1.67$ vs $0.55 \pm 1.11 ; \mathrm{p}=0.009)$ than those without risk of fall. There were correlations between the TPOMA scores and NRS for foot pain $(r=-0.264 ; \mathrm{p}=0.013)$ and number of foot deformities $(r=$ $-0.374 ; \mathrm{p}=0.001)$.

Conclusion: The results of this study demonstrate that $R A$ patients with foot pain/deformities have higher risk of fall. We suggest that early diagnosis and better control of disease activity will prevent foot pain/deformities in order to reduce the risk and the burden of falls.
\end{abstract}

Keywords: Foot deformities, foot pain, rheumatoid arthritis, risk of fall

WIMJ Open 2015; 2 (2): 81

\section{INTRODUCTION}

Patients with rheumatoid arthritis (RA) have an increased risk of falls compared with healthy controls for a variety of reasons, including the presence of lower limb joint involvement resulting in impaired mobility, balance and postural stability (1-3). To design appropriate intervention strategies to prevent falls and fall-related injuries, it is essential to gain further insight into the mechanisms underlying falls in patients with RA. The risk factors for falls in patients with RA that have been drawn from previous studies include pain in the lower extremities $(4,5)$, physical disability score $(1,4$, $6,7)$, impaired general health $(6,7)$ and impaired balance $(3)$. Foot problems including pain and deformities are highly prevalent and affect the majority of patients with RA (8). Foot problems are strongly associated with severe disability

From: Departments of ${ }^{1}$ Physical Medicine and Rehabilitation, ${ }^{2}$ Radiology and ${ }^{3}$ Family Medicine, Faculty of Medicine, Mustafa Kemal University, Hatay, Turkey.

Correspondence: Dr MT Yildizgoren, Department of Physical Medicine and Rehabilitation, Faculty of Medicine, Mustafa Kemal University, Hatay, Turkey. E-mail: ftr.mustafaturgut@hotmail.com because the inflammatory process within the synovial tissue including foot joints and tendons leads to joint destruction and subsequent deformity (9).

Most research on foot pain/deformities associated with fall has focussed on the elderly. Compared with younger persons, they have increased risk of fall because of increased foot problems $(10,11)$. However, little is known about the influence of foot pain/deformities on risk of fall in the patients with RA. Therefore, the objective of this study was to determine the influence of foot pain/deformities on risk of fall in patients with rheumatoid arthritis.

\section{SUBJECTS AND METHODS}

This cross-sectional study comprised 89 patients ( 75 females, 14 males) with RA according to the 1987 criteria of the American College of Rheumatology. Patients were recruited consecutively from visitors to the outpatient rheumatology clinic of our department. Patients who had neurological conditions, co-morbities (cardiac disease, hypertension, diabetes mellitus, thyroid disease and pulmonary disease), joint prostheses in the lower extremities, vision impairment, and who were using antidepressants and sedatives were excluded (5). 
The study was approved by the ethical committee of the University and all participants gave written informed consent.

Demographic variables, disease duration, walking aids, medication use, numeric rating scale [NRS] $(0-10 \mathrm{~cm})$ for general health, global disability using the Health Assessment Questionnaire (HAQ), morning stiffness (minute), erythrocyte sedimentation rate $[E S R](\mathrm{mm} / \mathrm{h})$, C-reactive protein [CRP] $(\mathrm{mg} / \mathrm{dL})$, rheumatoid factor [RF] (IU/ml), number of swollen/tender joints and disease activity score using the Disease Activity Score in 28 joints (DAS28) were recorded. Patients were asked about the occurrence of falls in the last 12 months.

The patients were queried about pain in the hip, knee and foot by asking whether they had pain in each site in the past 15 days and were asked to rate the average pain in each site using a $10 \mathrm{~cm}$ NRS.

The diagnoses of foot deformities were based on the clinical and radiographic evaluation under standardized weight-bearing conditions. Radiographic examination included weight-bearing anteroposterior, lateral and medial oblique views of the foot and ankle. Foot deformity score was recorded using the zero to eight semi-quantitative scoring system, with one point added for every instance, on either foot, of hallux valgus, hammer toe, claw toe or flat foot on either foot.

The patients' risk of fall was assessed using the Tinetti Performance Oriented Mobility Assessment (TPOMA), which is scored on the patient's ability to perform specific tasks containing both a balance and a gait component (12). The balance component of the test assesses the patient's ability to maintain postural control while sitting statically, while rising from a chair, during the period immediately after standing, while standing with eyes open and eyes closed, while turning $360^{\circ}$ and during perturbation. The gait component assesses symmetry, initiation, continuity, path, base of support and postural sway during gait. Scoring of TPOMA tool is done on a three-point ordinal scale with a range of zero to two. A score of zero represents highest degree of impairment, whereas two would represent independence of the patient. The maximum score for the gait component is 12 points. The maximum score for the balance component is 16 points. The maximum total score is 28 points. In general, patients who score below 19 are at high risk for falls. Patients who score in the range of 19-24 indicate a risk for falls (12). All participants were grouped according to TPOMA scores; scores less than and equal to 24 were accepted as risk of fall while over 24 were accepted as normal.

\section{Statistical analysis}

Statistical analysis was performed using the SPSS version 15.0 for Windows (SPSS Inc, Chicago, IL, USA). Statistical significance of the differences between groups was determined with the Mann-Whitney U test (continuous variables) and the Chi-squared test for independence (counts) when appropriate. The correlation analysis between variables was evaluated by Spearman's correlation analysis. A $p$-value of $<$ 0.05 was considered statistically significant.

\section{RESULTS}

Eighty-nine patients with RA ( 74 females, 15 males, mean age $46.84 \pm 13.20$ years) participated in the study. Mean disease duration was $7.82 \pm 7.01$ years. All patients with RA were managed on disease-modifying anti-rheumatic drug therapy and $11(12 \%)$ patients were receiving biologic drug therapy. Twenty-nine (32.6\%) patients were using steroids (mean dose of prednisolone $5 \mathrm{mg} /$ day). All of the patients were able to walk without a walking aid. The mean DAS28 score of the patients was $4.64 \pm 1.14$ (moderate disease activity). Twelve (13\%) patients had a risk of fall according to TPOMA (TPOMA score $\leq 24$ ).

Twenty (22\%) patients had hip pain, 51 (57\%) patients had knee pain and $55(62 \%)$ patients had foot pain. There were no significant differences between the patients with risk of fall in terms of number of patients with or without hip pain (3 vs $6 ; p=0.735)$, knee pain ( $2 v s 7 ; p=0.722)$ and foot pain (9 vs $0 ; p=0.093$ ). Twenty-seven (30\%) patients had $\geq 1$ foot deformities. Among the patients with foot deformity, 18 (67\%) patients had two foot deformities. Thirteen (15\%) patients had hallux valgus, $14(16 \%)$ patients had pes planovalgus, four $(4 \%)$ patients had hammer toe and one $(1 \%)$ patient had claw toe. There were no statistically significant differences between the patients with and without risk of fall in terms of demographic data, disease duration, streoid use, falling history and for general health.

Although number of swollen/tender joints and NRS for hip and knee pain was higher, there were no statistically significant differences between the groups (Table). The risk for fall group showed higher mean CRP level, RF level, DAS28 score and duration of morning stiffness than the nonfall risk group, yet there were no statistically significant differences between the groups.

The patients with risk of fall had a higher HAQ score $(2.55 \pm 1.54 v s 1.14 \pm 1.12 ; p=0.009)$, NRS for foot pain $(4.08 \pm 1.44$ vs $2.62 \pm 2.51 ; p=0.012)$ and number of foot deformities $(1.41 \pm 1.67 v s 0.55 \pm 1.11 ; p=0.009)$ than those without risk of fall (Figure). Twenty-five (92\%) patients with foot deformities had foot pain $(p=0.018)$. There were correlations between the TPOMA scores and HAQ scores ( $\mathrm{r}$ $=-0.278 ; p=0.019)$, foot pain NRS $(\mathrm{r}=-0.264 ; p=0.013)$ and number of foot deformities $(\mathrm{r}=-0.374 ; p=0.001)$.

Nine $(10 \%)$ patients reported at least one fall during the preceding 12 -month period. There were no significant differences between the patients with or without fall report in terms of NRS for foot pain $(2.75 \pm 2.23$ vs $2.84 \pm 2.28 ; p=0.963)$ and the number of foot deformities $(0.25 \pm 0.46$ vs $0.38 \pm$ $0.66 ; p=0.679)$. There was no significant difference between the patients with fall report in terms of percentage of the patients with foot pain $(p=0.794)$ and foot deformity ( $p$ $=0.743$ ). 
Table: Demographic and clinical characteristics for rheumatoid arthritis patients with or without risk of fall

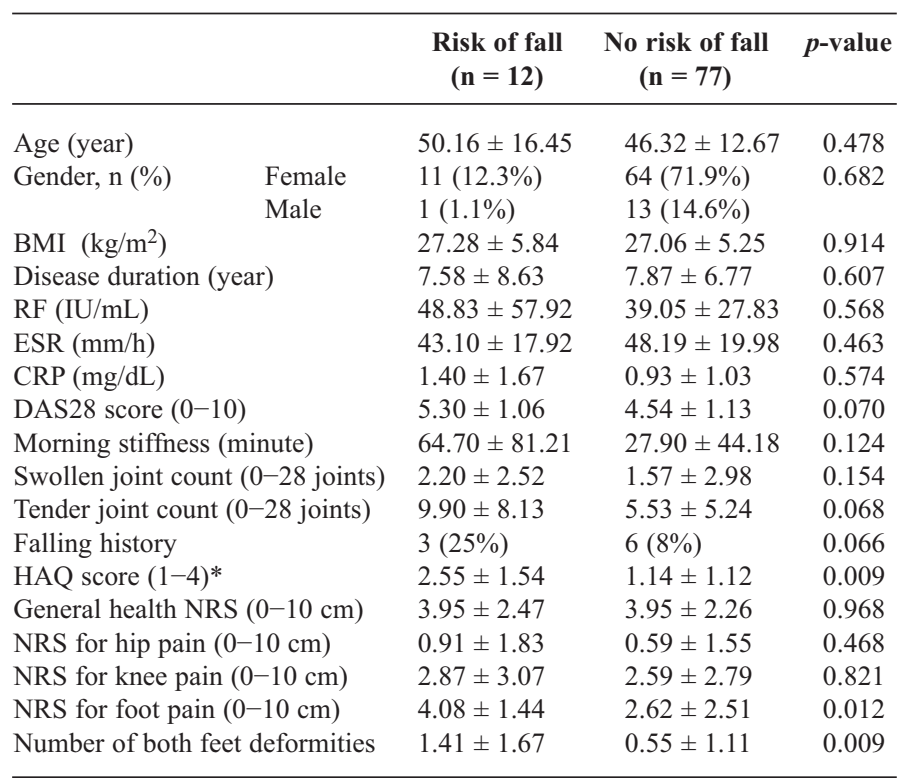

BMI: body mass index; RF: rheumatoid factor; ESR: erythrocyte sedimentation rate; CRP: C-reactive protein; DAS28: Disease Activity Score in 28 joints; HAQ: Health Assessment Questionnaire; NRS: numeric rating scale. *Higher HAQ score indicates higher disability.

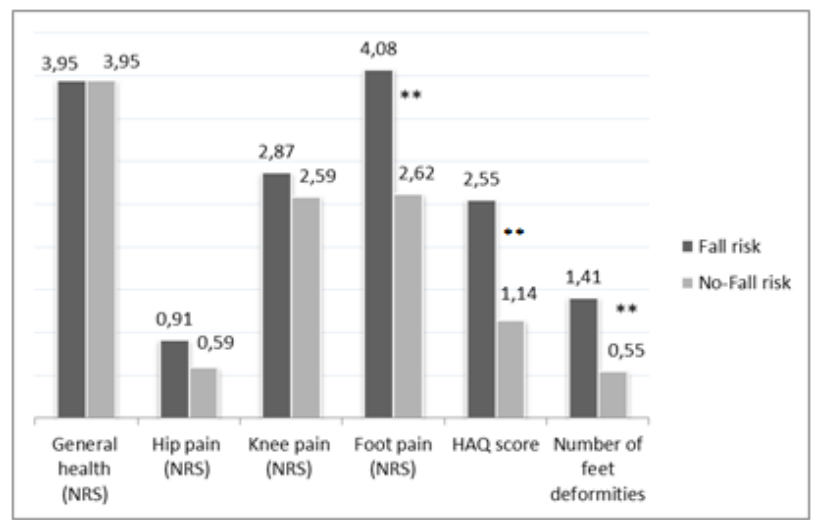

Figure: Comparison of numeric rating scale (NRS), Health Assessment Questionnaire (HAQ) values and number of both feet deformities for rheumatoid arthritis (RA) patients with or without risk of fall. Although the NRS (knee-hip-foot) values were higher in RA patients with risk of fall, it reached significance only in the NRS for foot $(* * p<0.05)$. There were significant differences between the groups regarding HAQ score and number of feet deformities.

\section{DISCUSSION}

Due to the high risk of falls, it is important to highlight risk factors that may be modified to prevent falls in patients with RA. The aim of this study was to investigate whether there was a relationship between foot pain/deformities and risk of fall in the patients with RA. Results of this study showed that $12(13 \%)$ patients had risk of fall. Numeric rating scale for foot pain and number of the foot deformities were higher in the patients with risk of fall. The risk of fall scores were negatively correlated with the NRS for foot pain and number of foot deformities. To the best of our knowledge, this is the first study that investigated the relationship between foot pain/deformities and the risk of fall in patients with RA.

Kaz Kaz et al (1) found that the risk of fall was $89 \%$ in the patients with RA. In the present study, the risk of fall was found to be $13 \%$ using TPOMA. Low risk of fall in this study could be explained by the exclusion criteria of the study that included other risk factors for falls in addition to low mean age of the patients involved in the study.

It has been reported that chronic musculoskeletal pain increases the risk of fall $(13,14)$. Foot pain is a risk factor for falls in relation to immobility, muscle weakness, slowed reaction time, gait and balance disturbances $(2,3,15-18)$. In the present study, NRS for foot pain - not hip or knee pain was found to be associated with risk of fall in the patients with RA. This result is similar to the data presented by Grondal et al (8) who demonstrated that pain in the lower extremity is a risk factor for fall in patients with RA.

Rheumatoid foot commonly manifests in the joints of the forefoot in the early stages, and midfoot and hindfoot in the later stages of the disease. Foot involvement results in foot deformity in the majority of the patients within 10 years of the disease (9). Once hallux valgus has developed, a simple biomechanical model can explain that the deformity will probably progress. A severe valgus deformity of the foot occurs in 10 to $30 \%$ and lowering of the medial longitudinal arch in $50 \%$ of patients with chronic RA (19). The incidence and severity of foot deformities in patients with RA increase in the chronic stages $(9,20)$. In this study, the percentage of patients who had foot deformities was low. Fifteen per cent of the patients in this study had hallux valgus, $16 \%$ of the patients had pes planovalgus. This low percentage of patients with foot deformities may be explained by short disease duration (eight years) of the patients in this study.

Lower limb disability is a risk factor for falls in the patients with RA (2). The foot is the most important part of the lower extremity causing reduced walking capacity (8). The varying degrees of foot joints destruction associated with RA result in lower limb disability in relation to postural instability, gait and balance disturbances $(2,3,5,9,19,21$, 22). Data presented in the present study demonstrated that there was also a positive correlation between the number of foot deformities and risk of fall in the patients with RA.

Foot deformities are common conditions that may lead to considerable pain and disability (23). In this study, almost all of the patients with foot deformities had foot pain. The number of patients with foot deformities without foot pain was very low. This result is consistent with the data presented by Yamagiwa et al (24) who demonstrated that both inflammatory and mechanical factors are thought to be important drivers of foot-related impairment and disability in patients with RA. 
In the current study, there were no significant differences in patients with or without risk of fall in terms of increases in acute phase reactants, swollen joint count, RF and DAS28 score. These results are consistent with the data presented by several authors $(1,7,25)$ who demonstrated no correlation between objective measures of disease activity (increases in acute phase reactants and swollen joint count) and risk of fall. Impaired general health (5-7) and increasing HAQ disability score $(1,4-7,25)$ are significantly associated with an increased risk of fall. In this study, impaired general health and increasing HAQ disability score were also significantly associated with an increased risk of fall.

Armstrong et al (2) found the incidence of fall to be $34 \%$. In the present study, nine $(10 \%)$ patients reported at least one fall during the preceding 12 -month period. Low fall report in the present study could be explained by the aforementioned exclusion criteria of the study in addition to the low mean age of the patients. Retrospective studies seem to under-estimate the prevalence of falls because patients gradually tend to forget their falls (26). This could also be another reason for the low fall report in our study. In the present study, there were no significant differences in NRS for foot pain and the number of foot deformities between the patients with or without fall report in the previous one year. This result could be explained by foot pain/deformities in this study reflecting the current status and not including the previous one year.

Early diagnosis and better control of disease activity could prevent deformities and falls. In the present study, all of the patients had taken disease-modifying anti-rheumatic drugs and a substantial number was on biologic drugs. Although both groups have taken drug treatment, DAS28 score was high. It perhaps could reflect inadequate or too late treatment.

\section{CONCLUSION}

The results of this study demonstrate that RA patients with foot pain/deformities have higher risk of fall. We suggest that early diagnosis and better control of disease activity could prevent foot pain/deformities in order to reduce the risk of and the burden of falls. However, further well-designed prospective studies with a larger number of patients are needed to confirm this result.

\section{REFERENCES}

1. Kaz Kaz H, Johnson D, Kerry S, Chinappen U, Tweed K, Patel S. Fallrelated risk factors and osteoporosis in women with rheumatoid arthritis. Rheumatology (Oxford) 2004; 43: 1267-71.

2. Armstrong C, Swarbrick CM, Pye SR, O’Neill TW. Occurrence and risk factors for falls in rheumatoid arthritis. Ann Rheum Dis 2005; 64: $1602-4$.

3. Hayashibara M, Hagino H, Katagiri H, Okano T, Okada J, Teshima R. Incidence and risk factors of falling in ambulatory patients with RA: a prospective 1-year study. Osteoporos Int 2010; 21: 1825-33.

4. Fessel KD, Nevitt MC. Correlates of fear of falling and activity limitation among persons with rheumatoid arthritis. Arthritis Care Res 1997; 10: 222-8.

5. Stanmore EK, Oldham J, Skelton DA, O’Neill T, Pilling M, Campbell AJ et al. Risk factors for falls in adults with rheumatoid arthritis: a prospective study. Arthritis Care Res (Hoboken) 2013; 65: 1251-8.

6. Oswald AE, Pye SR, O’Neill TW, Bunn D, Gaffney K, Marshall T et al. Prevalence and associated factors for falls in women with established inflammatory polyarthritis. J Rheumatol 2006; 33: 690-4.

7. Furuya T, Yamagiwa K, Ikai T, Inoue E, Taniguchi A, Momohara S et al. Associated factors for falls and fear of falling in Japanese patients with rheumatoid arthritis. Clin Rheumatol 2009; 28: 1325-30.

8. Grondal L, Tengstrand B, Nordmark B, Wretenberg P, Stark A. The foot: still the most important reason for walking incapacity in rheumatoid arthritis. Distribution of symptomatic joints in 1,000 RA patients. Acta Orthop 2008; 79: 257-61.

9. Jaakkola JI, Mann RA. A review of rheumatoid arthritis affecting the foot and ankle. Foot Ankle Int 2004; 25: 866-74.

10. Mickle KJ, Munro BJ, Lord SR, Menz HB, Steele JR. ISB Clinical Biomechanics Award 2009: toe weakness and deformity increase the risk of falls in older people. Clin Biomech (Bristol, Avon) 2009; 24: 787-91.

11. Deandrea S, Lucenteforte E, Bravi F, Foschi R, La Vecchia C, Negri E. Risk factors for falls in community-dwelling older people: a systematic review and meta-analysis. Epidemiology 2010; 21: 658-68.

12. Tinetti ME. Performance-oriented assessment of mobility problems in elderly patients. J Am Geriatr Soc 1986; 34: 119-26.

13. Leveille SG, Bean J, Bandeen-Roche K, Jones R, Hochberg M, Guralnik JM. Musculoskeletal pain and risk for falls in older disabled women living in the community. J Am Geriatr Soc 2002; 50: 671-8.

14. Leveille SG, Jones RN, Kiely DK, Hausdorff JM, Shmerling RH, Guralnik JM et al. Chronic musculoskeletal pain and the occurrence of falls in an older population. JAMA 2009; 302: 2214-21.

15. Mickle KJ, Munro BJ, Lord SR, Menz HB, Steele JR. Foot pain, plantar pressures, and falls in older people: a prospective study. J Am Geriatr Soc 2010; 58: 1936-40.

16. Menz HB, Morris ME, Lord SR. Foot and ankle risk factors for falls in older people: a prospective study. J Gerontol A Biol Sci Med Sci 2006; 61: $866-70$

17. Wickham C, Cooper C, Margetts BM, Barker DJ. Muscle strength, activity, housing and the risk of falls in elderly people. Age Aging 1989; 18: 47-51.

18. Jamison M, Neuberger GB, Miller PA. Correlates of falls and fear of falling among adults with rheumatoid arthritis. Arthritis Rheum 2003; 49: $673-80$.

19. Kerry RM, Holt GM, Stockley I. The foot in chronic rheumatoid arthritis: a continuing problem. The Foot 1994; 4: 201-3.

20. Matricali GA, Boonen A, Verduyckt J, Taelman V, Verschueren P, Sileghem A et al. The presence of forefoot problems and the role of surgery in patients with rheumatoid arthritis. Ann Rheum Dis 2006; 65: 1254-5.

21. Woodburn J, Udupa JK, Hirsch BE, Wakefield RJ, Helliwell PS, Reay $\mathrm{N}$ et al. The geometric architecture of the subtalar and midtarsal joints in rheumatoid arthritis based on magnetic resonance imaging. Arthritis Rheum 2002; 46: 3168-77.

22. Dubbeldam R, Nene AV, Buurke JH, Groothuis-Oudshoorn CG, Baan $\mathrm{H}$, Drossaers-Bakker KW et al. Foot and ankle joint kinematics in rheumatoid arthritis cannot only be explained by alteration in walking speed. Gait Posture 2011; 33: 390-5.

23. Menz HB, Lord SR. Gait instability in older people with hallux valgus. Foot Ankle Int 2005; 26: 483-99.

24. Yamagiwa K, Iijima S, Furuya T, Ikai T, Inoue E, Taniguchi A et al. Incidence of falls and fear of falling in Japanese patients with rheumatoid arthritis. Mod Rheumatol 2011; 21: 51-6.

25. Böhler C, Radner H, Ernst M, Binder A, Stamm T, Aletaha D et al. Rheumatoid arthritis and falls: the influence of disease activity. Rheumatology (Oxford) 2012; 51: 2051-7. 
26. Cummings SR, Nevitt MC, Kidd S. Forgetting falls. The limited accuracy of recall of falls in the elderly. J Am Geriatr Soc 1988; 36: 613-6.
Received 28 Aug 2014

Accepted 07 Jan 2015

Published 28 May 2015

Online: http://www.mona.uwi.edu/wimjopen/article/1639

(C) Guler et al 2015

This is an open access article made freely available under Creative Commons Attribution 4.0 International (CC BY 4.0). Users are free to share, copy and adapt this work as long as the copyright holder (author) is appropriately and correctly credited. See http://creativecommons.org/ licences/by/4.0/deed.en_us for more information. 